九州大学学術情報リポジトリ

Kyushu University Institutional Repository

\title{
Identification of Recent Bats belonging to the Rhinolophidae by the Humeral Characters
}

Yoon, Myung Hee

Zoological Laboratory, Faculty of Agriculture, Kyushu University

Uchida, Teruaki

Zoological Laboratory, Faculty of Agriculture, Kyushu University

https://doi.org/10.5109/23784

出版情報：九州大学大学院農学研究院紀要. 28 (2/3)，pp. 135-146，1983-12. Kyushu University バージョン：

権利関係 : 
J. Fac. Agr., Kyushu Univ., 28(2•3), 135-146 (1983)

\title{
Identification of Recent Bats belonging to the Rhinolophidae by the Humeral Characters
}

\author{
Myung Hee Yoon and Teru Aki Uchida \\ Zoological Laboratory, Faculty of Agriculture, \\ Kyushu University 46-06, Fukuoka 812
}

(Received October 7, 1983)

\begin{abstract}
Humeral characters of eleven recent species and one subspecies belonging to three genera of the Rhinolophidae including two subfamilies were described. A key provides for their identification as well as the identification of the fossil bats found on the Akiyoshi-dai Plateau. Further, we discussed differences in the adaptability for flight of the bats not only within each taxon of the family but also between the phylogenetically less advanced Rhinolophidae and the more advanced Vespertilionidae, taking the value of DW/PW (the ratio of the distal epiphysis width to the proximal one) and the wing-type ratio (the third finger to the fifth one) into consideration. In consequense, as a rule, the more the bat was in a phylogenetically high position, the more the adaptability for flight was high.
\end{abstract}

\section{INTRODUCTION}

A number of humeri of fossil bats, which occupy a great part of the fossil skeleton, have been found on the Akiyoshi-dai Plateau and consequently the identification of the fossil bats to the species level by only the humeral characters became necessary. It has been well known that the humerus exhibits the property of the family, subfamily, genus and species (Miller, 1907; Revilliod, 1922; Lawrence, 1943; Vaughan, 1959, 1970; Sigé, 1971; Yoon et al., 1981; Yoon and Uchida, 1983). In this connection, Yoon and Uchida (1983) made clear the fact that 23 species of nine genera belonging to the Vespertilionidae including three subfamilies can be classified by only the humeral characters. They also dealt with the adaptability for flight within each taxon of the Vespertilionidae using the value of $\mathrm{DW} / \mathrm{PW}$ (the ratio of the distal epiphysis width to the proximal one) as well as the wing-type ratio (the third finger to the fifth one).

The aim of the present study was to classify the members belonging to the Rhinolophidae by the humeral characters. Furthermore, we discussed the difference in the adaptability for flight both between the Rhinolophidae and the Vespertilionidae, and within each taxon of the Rhinolophidae.

\section{MATERIALS AND METHODS}

We studied the right humeri, as a rule, of Rhinolophidae available, includ- 
ing six species and one subspecies of Rhinolophus belonging to the Rhinolophinae, and the single species of Asellia and four species of Hipposideros belonging to the Hipposiderinae (see Tables 1 and 2). Since we found no differences between two subspecies of Rhinolophus ferrumequinum nippon and R. $\mathbf{f}$. korai, they were included together in the species concerned.

With respect to the humeri of the species examined, the humerus length (HL), proximal epiphysis width (PW) and distal epiphysis width (DW) were measured by a caliper with $1 / 20 \mathrm{~mm}$ precision, and then the value of $\mathrm{DW} / \mathrm{PW}$ was calculated. The wing-type ratio also was estimated.

\section{DESCRIPTIONS}

\section{Family Rhinolophidae}

The Rhinolophidae inhabiting Japan is composed of members belonging to Rhinolophus (Rhinolophinae) and Hipposideros (Hipposiderinae). The humeri of the Rhinolophidae examined (Rhinolophus, Asellia and Hipposideros) possess the following characteristics (Fig. 1). The humeral shaft (s) is slightly sigmoid in lateral view. The trochiter (tr) curves laterad and projects beyond the head (h). The trochin $(\operatorname{tn})$ is lower than the trochiter. The anterior pit (ap, the pit immediately anterior to the head) is shallow and the medial ridge $(\mathrm{mr})$ is undeveloped or slightly developed. The lateral knob is undeveloped and the pectoral ridge (pr) is knife-like in appearence. The capitulum (c) consists of the inner (ir) and lateral (lr) ridges divided by a lateral groove. Another inner groove, which is nearly parallel to the humeral axis as well as the above one, separates the inner ridge of the capitulum from the trochlea (ta). The trochlea is sharp on the margin and the medial epicondyle (me) is wide. The spinous process ( $\mathrm{sp}$ ) is peg-like in appearence. The distal epiphysis is very wide, and both the distal articular surface and the radial fossa (rf) are remarkably eccentric outwards against the humeral axis. The lateral epicondylar crest is absent, and both the olecranon fossa (of) and the radial fossa are shallow. The value of $\mathrm{DW} / \mathrm{PW}$ is 1.33-0. 99.

Key to the subfamilies and genera of Rhinolophidae examined on the basis of the humeral morphology

1. Head taking the form of an inverted triangle with rotundity; groove between the capitular inner ridge and lateral one very deep. DW/PW: 1.33-1. 16.........................................Rhinolophinae (Rhinolophus)

1'. Head oval; groove between the capitular inner ridge and lateral one

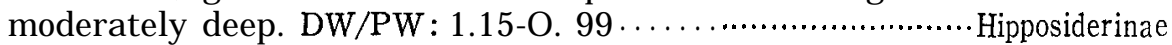

2. Shaft slender, compressed except in distal part, apex of head pointing laterad and caudad; trochiter relatively high; medial ridge scarcely developed; spinous process curved laterad, relatively long. DW/

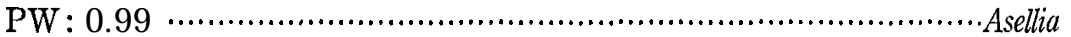

2 '. Shaft moderately thick, cylindrical except in distal part; apex of head pointing caudad; trochiter relatively low; medial ridge slightly 
Table 1. Comparison of the humerus and the wing-type in Rhinolophus species examined (Rhinolophinae).

\begin{tabular}{|c|c|c|c|c|c|}
\hline Species & $\mathbf{N}$ & (Rv. in $\mathrm{Hm})$ & $\begin{array}{c}\mathrm{DW} / \mathrm{P} W \\
\text { (Av.) }\end{array}$ & $\begin{array}{l}\text { Wing-type } \\
(\text { III } / V)\end{array}$ & Locality \\
\hline $\begin{array}{l}\text { Rhinninthiss cornutus } \\
\text { cormutus }\end{array}$ & 13 & $21.75-22.90$ & $1.17 .24)^{333}$ & $1.10=1.15$ & Japan \\
\hline R. monoceros & 2 & $21.50, \quad 22.40$ & $1.16, \quad 1.18$ & $1.14, \quad 1.14$ & Taiwan \\
\hline R. imaizumi & 3 & $22.4\left(22.61^{-}\right)^{05}$ & $1.17 .18)^{19}$ & $1.11-.16$ & Japan \\
\hline R. creaghi & 2 & $28.50, \quad 29.15$ & 1. 16, 1.19 & $1.25, \quad 1.25$ & Malaysia \\
\hline R. euryale euryale & 2 & 27. $45,27.60$ & $1.21, \quad 1.21$ & $1.26, \quad 1.29$ & Jugoslavia \\
\hline R. ferrumequinum & 12 & $\begin{array}{c}34.25-37.20 \\
(35.24)\end{array}$ & ${ }_{(1.21)}^{1.19-1.24}$ & $1.15-1.22$ & $\begin{array}{l}\text { Japan } \\
\text { Korea }\end{array}$ \\
\hline
\end{tabular}

HL. humerus length; DW/PW, ratio of the distal epiphysis width to the proximal one of the humerus; III/V, ratio of the third finger to the fifth one.

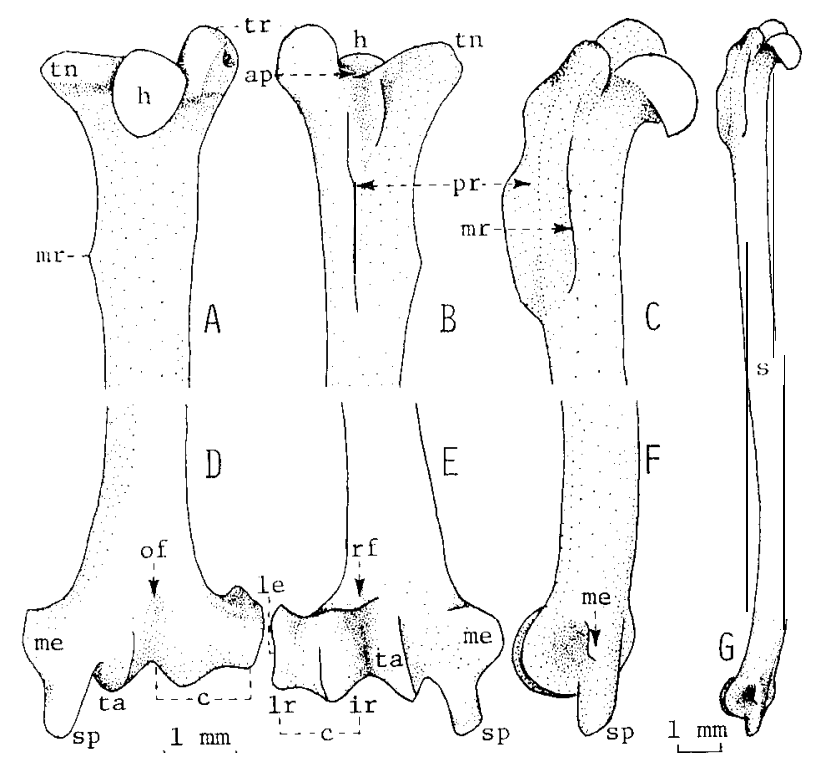

Fig. 1. Right humerus of Rhinolophus cormutus cornutus, showing posterior (A, D), anterior (B, E) and medial (C, F) views of proximal and distal ends, respectively, and a whole view (G). Left and right scales are for A-F and G, respectively. Abbreviations: ap, anterior pit; c, capitulum; h, head; ir, inner ridge of capitulum; le, lateral epicondyle; 1r, lateral ridge of capitulum; me, medial epicondyle; mr, medial ridge; of, olecranon fossa; pr, pectoral ridge; rf, radial fossa; s, shaft; sp, spinous process; ta, trochlea; tn, trochin; tr, trochiter. 
developed ; spinous process straight, relatively short. DW/PW: 1.15-

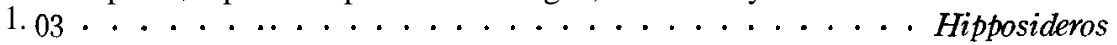

Subfamily Rhinolophinae Genus Rhinolophus

The humeral characteristics of three Japanese and three other foreign species are observed in this paper (Table 1 and Fig. 1).

Key to the species of Rhinolophus examined on the basis of the humeral morphology

1. Trochin nearly as high as head; pectoral ridge relatively high in lateral view; olecranon fossa vestigial.

2. Humerus length about $22 \mathrm{~mm}$; medial ridge terminated at nearly distal end of pectoral ridge; spinous process relatively long.

3 . Spinous process curved mediad $\ldots \ldots \ldots \ldots \ldots \ldots \ldots \ldots \ldots \ldots \ldots$. cornutus cornutus and $R$. monoceros

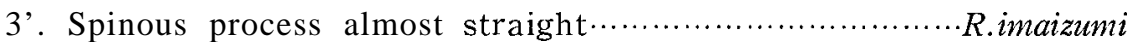

2'. Humerus length about $29 \mathrm{~mm}$; medial ridge terminated at higher level than distal end of pectoral ridge; spinous process relatively

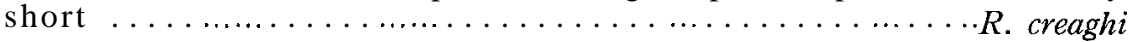

1'. Trochin slightly higher than head; pectoral ridge relatively low in lateral view; olecranon fossa relatively deep.

4. Humerus length about $27.5 \mathrm{~mm}$; spinous process relatively long....... . . . . . . . . . . . . . . . . . . . R. euryale euryale

4'. Humerus length about $35 \mathrm{~mm}$; spinous process relatively short .........

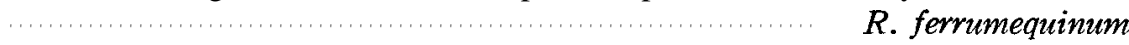

Subfamily Hipposiderinae

Genus Asellia

Regarding the single species, A. tridens (Table 2 and Fig. 2), the following humeral characteristics are added to those noted in the preceding key: the humerus is $29.25 \mathrm{~mm}$ in length; the medial ridge is terminated at higher level than the distal end of the pectoral ridge; the pectoral ridge is less than onesixth of the humerus in length; the capitular inner ridge is about three times as wide as the lateral one; and the olecranon fossa is relatively wide but shallow.

Table 2. Comparison of the humerus and the wing-type in Asellia and Hipposideros species examined (Hipposiderinae).

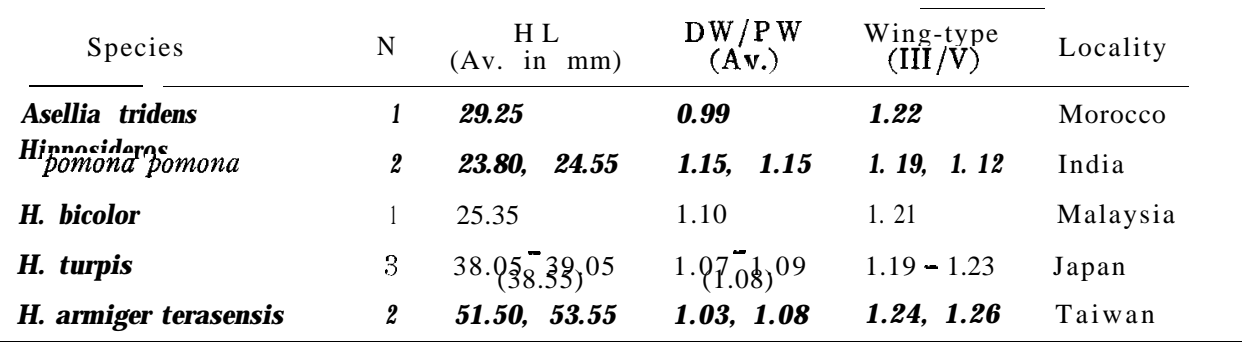

Abbreviations as in Table 1. 


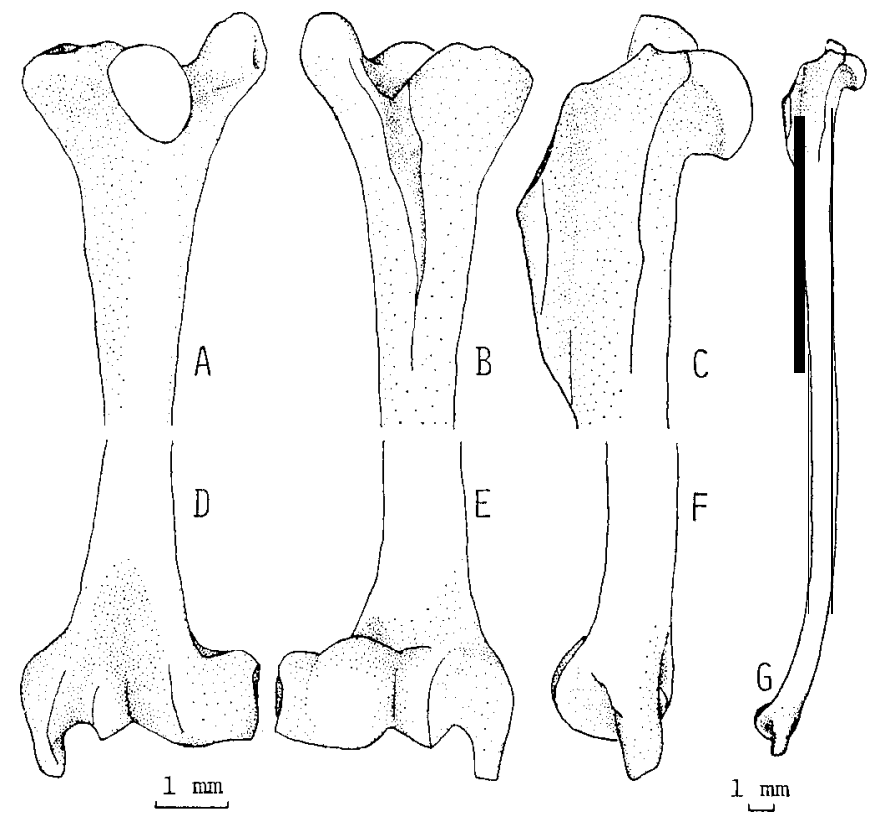

Fig. 2. Right humerus of Asellia tridens. Alphabetical symbols and scales as in Fig. 1.

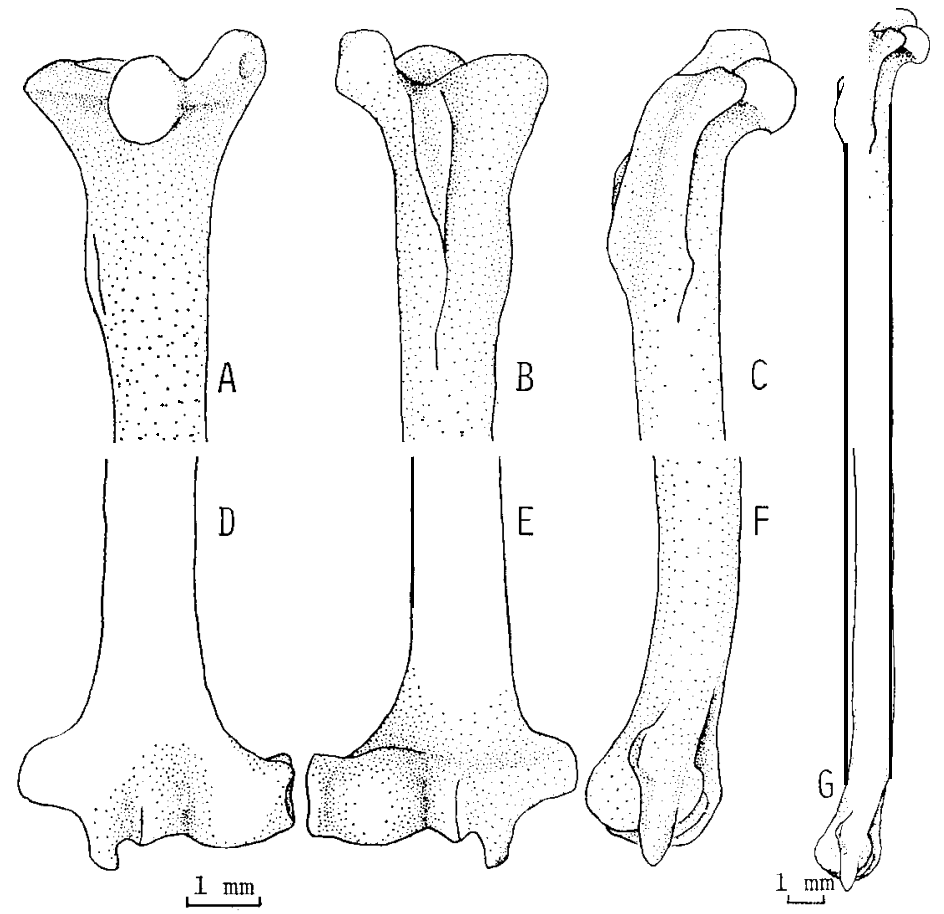

Fig. 3. Right humerus of Hipposideros pomona Pomona. Alphabetical symbols and scales as in Fig. 1. 
(icnus Hipposideros

The humeral characteristics of one Japanese species and three other foreign species are described in this paper (Table 2 and Fig. 3).

Key to the species of Hipposideros examined on the basis of

$$
\text { the humeral morphology }
$$

1. Humerus length about $25 \mathrm{~mm}$; pectoral ridge about one-seventh of humerus in length. DW/PW: $1.15-\mathrm{L} 10$.

2. Medial ridge terminated at nearly distal end of pectoral ridge; pectoral ridge more than one-seventh of humerus in length; olecranon fossa very shallow. DW/PW: $1.15 \ldots \ldots \ldots \ldots \ldots+. . \cdots$. pomona pomona

2'. Medial ridge terminated at slightly lower than distal end of pectoral ridge; pectoral ridge less than one-seventh of humerus in length; olecranon fossa relatively deep. DW/PW: 1. 10….............. bicolor

1. Humerus length more than $38 \mathrm{~mm}$; pectoral ridge about one-fifth of humerus in length. DW/PW: 1.09-1.03.

3 . Humerus length about $38 \mathrm{~mm}$; olecranon fossa relatively shallow ......

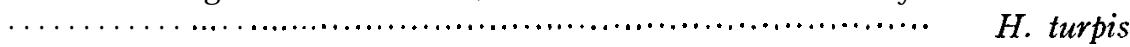

3'. Humerus length about $52 \mathrm{~mm}$; olecranon fossa relatively deep .... H. armiger terasensis

\section{DISCUSSION}

\section{Adaptive implication for flight between the Rhinolophidae and the Vesper- tilionidae}

Yoon and Uchida (1983) discussed the functional significance of the humeral morphology and the adaptation of bats for flight within each taxon belonging to the Vespertilionidae. There are essential differences in the humeral morphology between the phylogenetically less advanced Rhinolophidae having a maneuverable flight mode like a butterfly and the more advanced Vespertilionidae developing various flight modes. First, the pectoral ridge is very different in shape between the two families ; this is closely associated with the amount of muscles of the upper arm. For example, in the Rhinolophidae bearing a well-developed pectoral muscle, its anterior division inserts on the lateral border of the knife-like pectoral ridge, whereas in the Vespertilionidae that of the thin pectoral muscle inserts on the pedestal-like ridge. Thus, the thick biceps muscle passes through a shallow and wide groove in the Rhinolophidae, while the thin biceps muscle runs along a deeper and narrower groove in the Vespertilionidae.

Secondly, in the Rhinolophidae, since the distal articular surface is eccentric laterad against the humeral axis, the spinous process does not function as a reinforcing device and the radius reaches to the back when the wing is folded; the elbow joint is by no means strong, the mobile angle of the radius also is high, and these characteristics are, therefore, suitable for a slow and weak downstroke. In the Vespertilionidae, however, of which the spinous process is well developed generally and curved laterad, works as a locking 
apparatus and considerably restricts the movable angle of the radius; the elbow joint is strengthened, the movable angle of the radius becomes low, and thus a downstroke becomes speedy and strong.

Another important characteristic related closely to flight lies in the value of DW/PW, which is generally higher in the Rhinolophidae (0.99-1.33) than in the Vespertilionidae (0.64-1. 12) as shown in Fig. 4; moreover, there is a lowering tendency of the value in a sequence from the Rhinolophidae to the Vespertilionidae. The higher ratio indicates that the mobile force originated

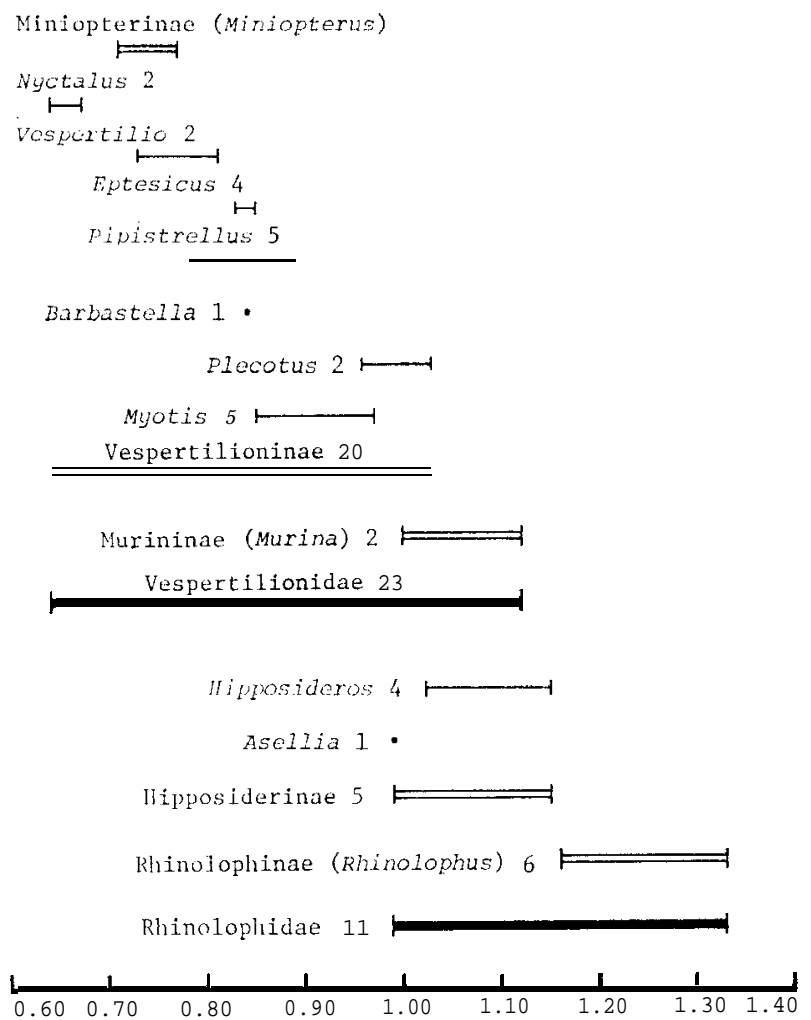

Fig. 4. Comparison of ranges of the DW/PW ratio between the Rhinolophidae including three genera of two subfamilies and the Vespertilionidae including nine genera of three subfamilies. The data in the Vespertilionidae are based on Yoon and Uchida (1983). Each numeral represents the number of species examined.

from the scapula and the sternum is transmitted to the upper arm more dispersedly and thus the wing-beat power becomes weaker, because the force passes through the wide distal epiphysis of the humerus bearing the broad insertion surface for muscles (Yoon and Uchida, 1983). From also the wing. type ratio (Fig. 5), it is pointed out that the Rhinolophidae with short-broad wings (1.10-1. 29) flies more slowly than the Vespertilionidae with interme- 
diate or long-narrow wings (1.19-I. 75) ; in contrast with the DW/PW, a heightening tendency of the ratio is visible in the same sequence. Thus, it became evident that the value of $\mathrm{DW} / \mathrm{PW}$ and the wing-type ratio are the most important criteria exhibiting the degree of adaptation, even though the bats belong to different families.

In fact, it has been revealed that Rhinolophus is a low-speed flier with a high maneuverability, compared with members of the Vespertilionidae (especially Miniopterus), from disparities in the number of the wing-beat, wing-loading (Kuramoto, 1972) and the myoglobin concentration (Ohtsu et al., 1978; Ohtsu and Uchida, 1979b), fiber composition (Ohtsu and Uchida, 1979a, b) and LDH isozyme pattern (Kitahara et al., 1974) of the pectoral muscle.
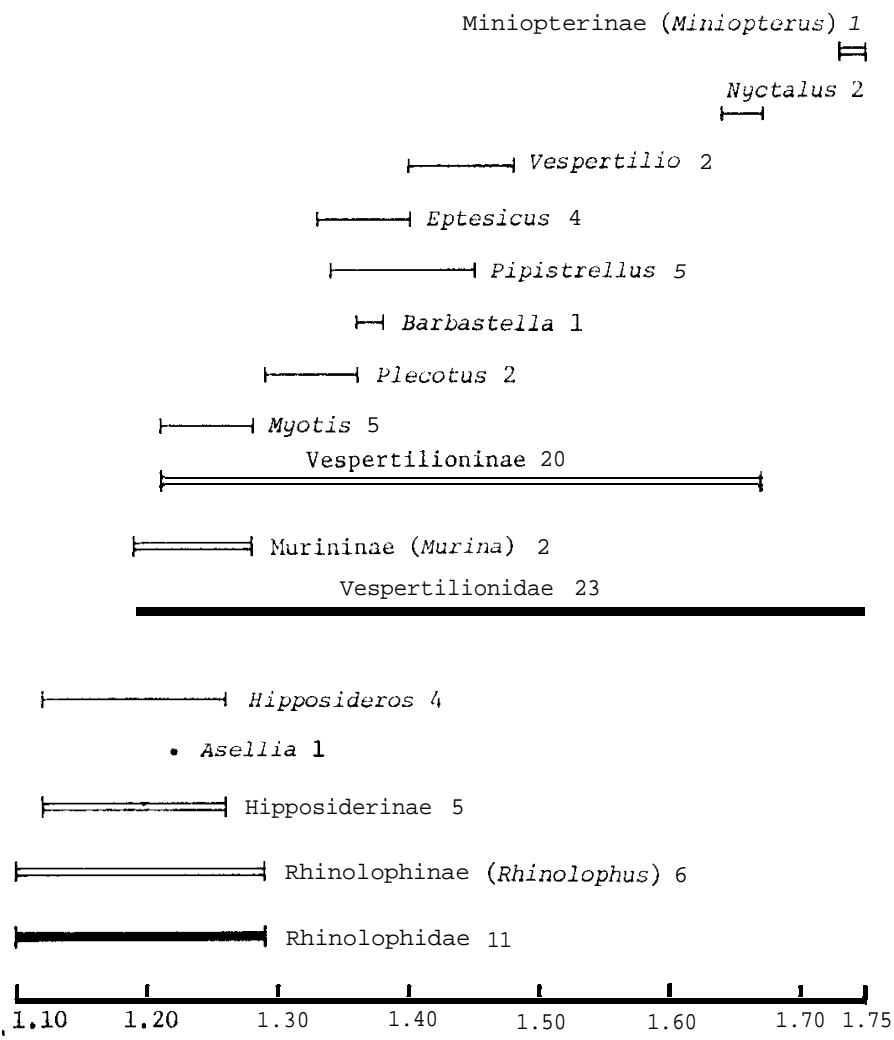

Fig. 5. Comparison of ranges of the wing-type ratio (III/V) between the Rhinolophidae and Vespertilionidae. Other explanations as in Fig. 4.

Adaptation for flight at the subfamily and generic levels within the Rhinolophidae

As for the taxonomical relationships between Rhinolophus and Hipposideros, Koopman and Jones (1970) and Ando (1982) placed the two genera in the Rhinolophinae and Hipposiderinae, respectively, although there was also an 
opinion that each of them belong to the Rhinolophidae and Hipposideridae (Miller, 1907).

Both the genera share the morphological properties to a considerable extent with each other. But, Hipposideros is characterized by the specialized characteristics, i. e. complication of the noseleaf (especially lower leaf), presence of the frontal sac above the upper noseleaf, degradation of the premolar (P") and molar $\left(\mathrm{M}^{3}\right)$, loss of the premolar $\left(\mathrm{P}_{3}\right)$, decrease in the number of the pedal phalanges and strengthening of the chest by the fusion of the sternoclavicular and sternocostal joints (Miller, 1907; Hill, 1963; Walton and Walton, 1970; Vaughan, 1972). Furthermore, Andō (1982) stated that Hipposideros is a more advanced form than Rhinolophus, on a hypothesis that both the genera descended from the same ancestor having a karyotype of $2 n=62$ and $\mathrm{FN}=60$.

Compared Rhinolophus and Hipposideros in the humeral characteristic, it is suggested that the latter is superior to the former in the flight speed judging from the lower value of DW/PW in Hipposideros; generally, the value of DW/ PW heightens in slow fliers, but lowers in fast fliers. However, it seems that both the genera are similar in the degree of maneuverability because of the similar wing-type ratio. Thus, also concerning the humerus, it is noted that

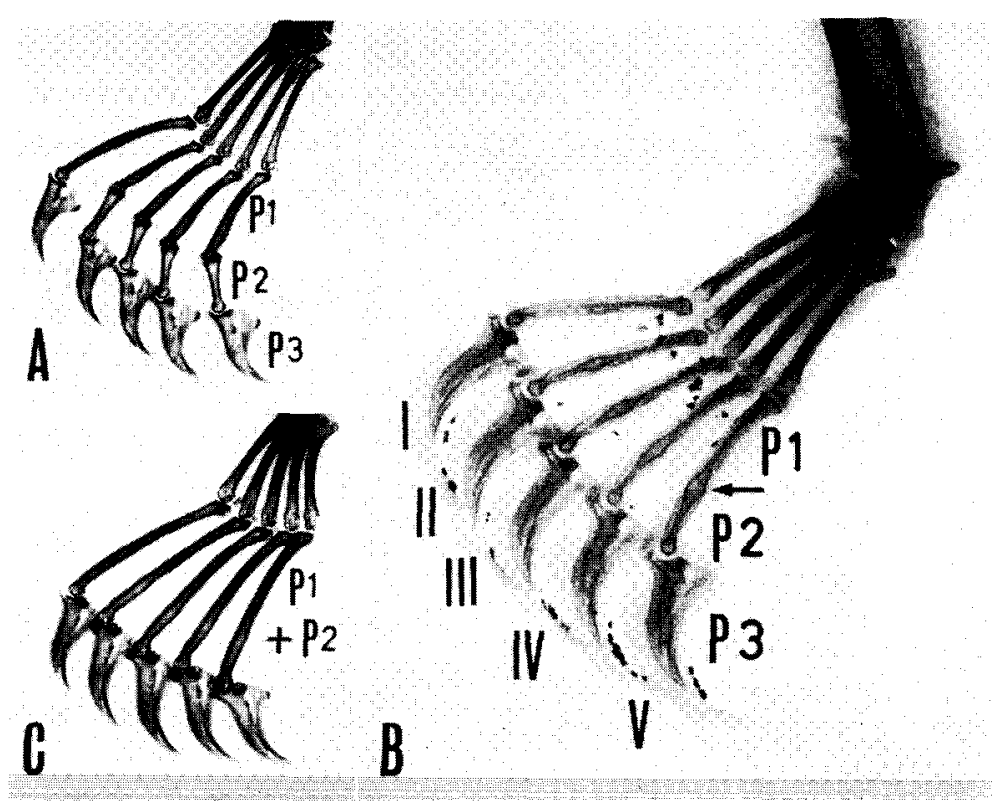

Fig. 6. Comparison of the pedal phalangeal articulation among Rhinolophus ferrumequinum (A), Asellia tridens (B) and Hipposiderosturpis (C). Note the vestiges of the interphalangeal articulation between the first and second phalanges from the second digit to fifth one in A. tridens (indicated by an arrow). A and $\mathrm{C} \times 3.4, \mathrm{~B} \times 6.8$ (by courtesy of Dr. K. Andō). Abbreviations: I, first digit; II, second digit; III, third digit; IV, fourth digit; V, fifth digit; P1, first phalanx; P2, second phalanx; P3, third phalanx. 
Rhinobphus retains the relatively primitive characteristics, whereas Hipposideros obtains the comparatively progressive characters, advancing further in the adaptability for flight.

Concerning the phylogenetical position of Asellia, it lies midway between Rhinolophus and Hipposideros. For example, the pedal interphalangeal articulation between the first and second phalanges from the second digit to fifth one is preserved perfectly in Rhinolophus, but in contrast, completely fused in Hipposideros, while it is fusing but remains the visible vestige in Asellia. Accordingly, it can be said that Asellia is a link of Rhinolophus and Hipposideros (Fig. 6). Miller (1907) regarded Asellia as a member of the Hipposideridae, but Koopman and Jones (1970) placed the genus in the Rhinolophinae (Rhinolophidae). Andō(1982), however, considered it a primitive genus originated from an ancestor of Hipposideros, and treated it as a member of the Hipposiderinae, judging from the karyotype $(2 \mathrm{n}=50, \mathrm{FN}=62)$.

We desire to regard Asellia as a component of the Hipposiderinae from the fact that the humerus, especially in the head and the capitulum, resembles in shape that of Hipposideros rather than Rhinolophus. Some humeral characters, e. g. the long trochiter and spinous process, and the low value of $\mathrm{DW} / \mathrm{PW}$, however, suggest that Asellia with strong joints of the shoulder and elbow is an advanced genus in the adaptability for flight, compared with Rhinolophus and Hipposideros, in spite of its phylogenetical position.

\section{Adaptability for flight in the five examined species of Rhinolophus}

The phylotaxonomy of Rhinolophus based on the external characters has been studied mainly by Andersen (1905 a, b, 1918), and Tate and Archbold (1939). Recently, Andō (1982) discussed the phylogenetical relationships, taking account of the karyology in addition to the external characters. He regarded species having the karyotype of $2 \mathrm{n}=62$ with a $\mathrm{FN}=60$ as primitive forms and species having the karyotype including biarmed autosomes as advanced forms, assuming that the ancestor form of Rhinolophus might have the karyotype, consisting of only acrocentric autosomes, of $2 \mathrm{n}=62$ and $\mathrm{FN}=60$. Moreover, it is a general trend that the larger the bat, the higher the phylogenetical position within Rhinolophus (Andō and Uchida, 1974). Based on the above accounts, $R$. c. cornutus (And6 and Uchida, 1974, $2 \mathrm{n}=62, \mathrm{FN}=60$ ), $R$. c. perditus $[=R$. imaizumi], R. monoceros (Andō et al., $1980,2 \mathrm{n}=62, \mathrm{FN}=60$ ) and $R$. creaghi (Harada and Kobayashi, 1980, $2 \mathrm{n}=62, \mathrm{FN}=60$ ) are the most primitive species, and $R$. euryale, $R$. $f$. ferrumequinum (Capanna and Civitelli, 1964, $2 \mathrm{n}=58, \mathrm{FN}=60$ ) and $R$. f. nippon (Ando and Uchida, 1974, $2 \mathrm{n}=58, \mathrm{FN}=62$ ) are arranged in ascending order of evolution.

On the other hand, it is plausible that the adaptability for flight of Rhinolophus examined has hardly altered from after its appearence to now, judging from little interspecific variation in the humeral morphology and the value of $\mathrm{DW} / \mathrm{PW}$ (Table 1). However, it seems that $R$. creaghi and $R$. e. euryale with a rather high wing-type ratio each, which are inferior to the other three species in the ability of maneuverability, have specialized toward fast flying. 


\section{Adaptability for flight in the four examined species of Hipposideros}

According to Hill (1963), who discussed the phylogenetical relationships between and within species groups, H. p. pomona and $H$. bicolor belonging to the bicolor group are regarded as primitive species, while H. turpis and H. $a$. terasensis of the armiger group are considered advanced ones. On the other hand, the karyotypes of nine Hipposideros species, reported so far, including $H$. turpis and $H$. armiger have the same $2 n$ (32) and FN (60) values, although slight differences are recognized among them in the composition of chromosome type. Further, since the karyotypes of $H$. p.pomona and $H$. bicolor have not yet been examined, it is difficult to discuss the karyotypic evolution among the Hipposideros species concerned.

As to the characters concerning the adaptability for flight, the value of $\mathrm{DW} / \mathrm{PW}$ is highest in $H$. p.pomona, and next in order are $H$. bicolor, H. turpis and $H$. a. terasensis, and the wing-type ratio is slightly higher in $H$. a. terasensis than in the other three species whose ratios resemble one another (Table 2). Hence, it may be said that the four species concerned have heightened the adaptability for flight in the above order, i. e. H. p. Pomona is the slowest flier with high maneuverability among the Hipposideros species examined, whereas H. a. terasensis is superior to the former in speed but inferior in the ability of maneuverability.

\section{ACKNOWLEDGEMENTS}

We wish to thank Dr. T. Kuramoto of the Akiyoshi-dai Museum of Natural History for his valuable advice, and Professor E. W. Jameson, Jr. of the University of California for comments on the manuscript. Thanks are also due to Professor P. Pirlot of the University of Montreal, Dr. H. Felten of the Forschungs-Institut Senckenberg, Dr. K. Andō of the University of Ryukyus and Mr. M. Harada of the Osaka City University for their kind supply of foreign specimens.

\section{REFERENCES}

Andersen, K. 1905a On some bats of the genus Rhinolophus, with remarks on their mutual affinities, and descriptions of twenty-six new forms. Proc. Zool.Soc. Lond., 2: 75 145

Andersen, K. 1905b On the bats of the Rhinolophus philippinensis group, with descriptions of five new species. Ann. Mag. Nat. Hist., 16: 243-258

Andersen, K. 1918 On new bats of the families Rhinolophidae and Megadermatidae. Ann. Mag. Nat. Hist., 2: 378-379

Andō, K. 1982 Karyotypic evolution and its phylotaxonomic implication in Chiroptera. Unpublished Ph. D. thesis. Fac. Agr. Kyushu Univ., 359pp. (in Japanese with English summary)

Andō, K. and T. A. Uchida 1974 Karyotype analysis in Chiroptera. II. Phylogenetic relationships in the genus Rhinolophus. Sci. Bull. Fac. Agr., Kyushu Univ., 28: 119-129 (in Japanese with English summary) 
Andō, K., T. Tagawa and T. A. Uchida 1980 Karyotypes of Taiwanese and Japanese bats belonging to the families Rhinolophidae and Hipposideridae. Cytologia, 45: 423432

Capanna, E. and M. V. Civitelli 1964 Contributo alla conoscenza della cariologia dei Rhinolofidi (Mammalia-Chiroptera). Caryologia, $17:$ 361-371

Harada, M. and T. Kobayashi 1980 Studies on the small mammals fauna of Sabah, East Malaysia. II. Karyological analysis of some Sabahan mammals (Primates, Rodentia, Chiroptera). Contri. Biol. Lab. Kyoto Univ., 26: 83-95

Hill, J. L. 1963 A revision of the genus Hipposideros. Bull. Brit. Mus. nat. Hist. (Zool.), 2: 1-129

Kitahara, E., 'T. A. Uchida and F. Hamajima 1974 LDH isozymes from the standpoint of adaptation for flight in Chiroptera. Zool.Mag., 83: 10-17 (in Japanese with English abstract)

Koopman, K. F. and J. K. Jones 1970 Classification of bats. In "About Bats," ed. by B. H. Slaughter and D. W. Walton, Southern Methodist University Press, Dallas, pp. 22-28

Kuramoto, T. 1972 Studies on bats at the Akiyoshi-dai Plateau, with special reference to the ecological and phylogenic aspects. Bull. Akiyoshi-dai Sci. Mus., (8) : $7-119$ (in Japanese with English abstract)

Lawrence, B. 1943 Miocene bat remains from Florida, with notes on the generic characters of the humerus of bats. J.Mamm., 24: 356-369

Miller, G. S. 1907 The families and genera of bats. Bull. U. S. natn. Mus., 57: I-282

Ohtsu, R. and T. A. Uchida 1979a Further studies on histochemical and ultrastructural properties of the pectoral muscles of bats. J.Fac. Agr., Kyushu Univ., 24: 145-155

Ohtsu, R. and T. A. Uchida 1979 b Correlation among fiber composition and LDH isozyme patterns of the pectoral muscles and flight habits in bats. J.Fac. Agr., Kyushu Univ., 24 : 157-163

Ohtsu, R., T. Mōri and T. A. Uchida 1978 Electron microscopical and biochemical studies on the major pectoral muscles of bats. Comp. Biockem. Physiol., 61A: 101-107

Revilliod, R. 1922 Contribution à l'étude des chiropteres des terrains tertiaires. Troisième partie et fin. Mém.Soc. Paléontol. Suisse, 45: 131-195

Sigé, B. 1971 Anatomie du membre antérieurchez un chiroptere molossidé (Tudarida sp.) du Stampien de Cereste (Alpes-de-Haute-Provence). Paleovertebrata, 4 : I-38

Tate, G. H. H. and R. Archbold 1939 Results of the Archbold expeditions. No. 24. Orien tal Rhinolophus, with special reference to material from the Archbold collections. Amer. Mus. Novitates (1036) : 1-12

Vaughan, T. A. 1959 Functional morphology of three bats: Eumops, Myotis, Macrotus. Univ. Kans. Pub., Mus. Nat. Hist., 12: 1-153

Vaughan, T. A. 1970 Adaptation for flight in bats. In "About Bats," ed. by B.H. Slaughter and D. W. Walton, Southern Methodist University Press, Dallas, pp. 127-143

Vaughan, 'T. A. 1972 Insectivores, dermopterans and bats. In “Mammalogy," W. B. Saunders Company, Philadelphia, London, Toronto, pp. 68-113

Walton, D. W. and G. M. Walton 1970 Postcranial osteology of bats. In "About Bats," ed. by B. H. Slaughter and D. W. Walton, Southern Methodist University Press, Dallas, pp. $93-126$

Yoon, M. H. and 'T.A. Uchida 1983 Identification of recent bats belonging to the Vespertilionidae by the humeral characters. J.Fac. Agr., Kyushu Univ., 28: 31-50

Yoon, M. H., T. Kuramoto and T. A. Uchida 1981 Studies on taxonomy and phylogeny of bats' fossils from the Akiyoshi-dai Plateau. I. Plecotus auritus and Barbastella leucomelas darjelingensis belonging to the tribe Plecotini. Bull. Akiyoshi-dai Mus. Nat. Hist., (16): 35-53 (in Japanese with English abstract) 